\title{
Ginseng administration protects skeletal muscle from oxidative stress induced by acute exercise in rats
}

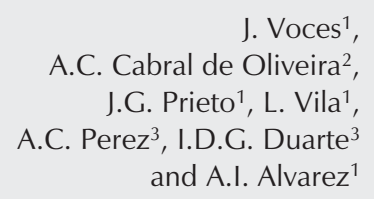

\author{
${ }^{1}$ Departamento de Fisiologia, Universidad de Leon, Leon, España \\ ${ }^{2}$ Departamento de Educação Física, Universidade Federal de Sergipe, \\ Aracaju, SE, Brasil \\ ${ }^{3}$ Departamento de Farmacologia, Universidade Federal de Minas Gerais, \\ Belo Horizonte, MG, Brasil
}

Correspondence

A.C. Perez

Departamento de Farmacologia

ICB, UFMG

Av. Antonio Carlos, 6627

31270-100 Belo Horizonte, MC

Brasil

Fax: +55-31-3499-2695

E-mail: acp@icb.ufmg.br

Received December 5, 2003

Accepted July 30, 2004

\begin{abstract}
Enzymatic activity was analyzed in the soleus, gastrocnemius (red and white) and plantaris muscles of acutely exercised rats after long-term administration of Panax ginseng extract in order to evaluate the protective role of ginseng against skeletal muscle oxidation. Ginseng extract $(3,10,100$, or $500 \mathrm{mg} / \mathrm{kg}$ ) was administered orally for three months to male Wistar rats weighing $200 \pm 50 \mathrm{~g}$ before exercise and to non-exercised rats ( $\mathrm{N}=8$ /group). The results showed a membrane stabilizing capacity of the extract since mitochondrial function measured on the basis of citrate synthase and 3-hydroxyacyl-CoA dehydrogenase activities was reduced, on average, by $20 \%(\mathrm{P}<0.05)$ after exercise but the activities remained unchanged in animals treated with a ginseng dose of $100 \mathrm{mg} / \mathrm{kg}$. Glutathione status did not show significant changes after exercise or treatment. Lipid peroxidation, measured on the basis of malondialdehyde levels, was significantly higher in all muscles after exercise, and again was reduced by about $74 \%(\mathrm{P}<0.05)$ by the use of ginseng extract. The administration of ginseng extract was able to protect muscle from exercise-induced oxidative stress irrespective of fiber type.
\end{abstract}

\section{Introduction}

Panax ginseng roots have been used in traditional Chinese medicine for their important therapeutic qualities. The pharmacological effects of ginseng have been demonstrated in the cardiovascular, immune, endocrine, and nervous systems (1). Until recently, the use of ginseng has been primarily empirical, but current systematic research has provided evidence for the antineoplastic
Key words

- Panax ginseng

- Exercise

- Free radicals

- Lipid peroxidation

- Glutathione status

- Mitochondria

.................... and antioxidant activity of the plant $(2,3)$. Most pharmacological actions of ginseng are attributed to ginsenosides, which are able to act on a wide range of tissues. Among all ginsenosides, $R b_{1}$ and $\mathrm{Rg}_{1}$ are the most effective compounds $(4,5)$. In addition, the non-ginsenoside constituents of ginseng also exert pharmacological effects (6). Ginsenosides are amphiphilic in nature and have the ability to become intercalated in the membrane environment $(1,7)$. 
There is evidence that the medicinal efficacy of ginseng is closely linked to its protective properties against free radical attack (8-10). $P$. ginseng administration to rats prevented myocardial ischemia-reperfusion damage induced by hyperbaric oxygen (9). Protective effects of $P$. ginseng against hepatic oxidative stress induced by exhaustive exercise (11) and against muscle injury and inflammation after eccentric exercise (12) have been reported. Ginseng extract has also been reported to scavenge superoxide radicals (13), to inhibit lipid peroxidation through transition metal chelation (7), and to reduce the oxidative DNA damage caused by the Fenton reagent (14).

Free radicals play an important role as mediators of skeletal muscle damage and inflammation after strenuous exercise and in the presence of muscle disease (15). It has been postulated that the generation of oxygen free radicals is increased during exercise as a result of increase in mitochondrial oxygen consumption and electron transport flux, inducing lipid peroxidation $(16,17)$. The adaptation of antioxidant enzymes is one of the main changes of skeletal muscle in response to exercise, much the same as mitochondrial oxidative enzyme adaptations $(18,19)$. The production of mitochondrial free radicals is also indirectly supported by the training adaptation of mitochondrial antioxidant enzymes, such as manganese-superoxide dismutase and glutathione (GSH) peroxidase (20).

Antioxidants are substances that help reduce the severity of oxidative stress either by forming a less active radical or by quenching the reaction. The literature suggests that dietary antioxidants may prevent muscle damage because they are able to detoxify some peroxides by scavenging reactive oxygen species produced during exercise (21). In fact, ingestion of antioxidant vitamins does result in lower resting and post-exercise levels of lipid peroxidation but does not prevent the exercise-induced oxidative stress (22).
Ginseng extract scavenges hydroxyl radicals and protects unsaturated fatty acids from oxidation, effects which may contribute to stabilizing the structure of the lipid membrane perturbed by free radical attack (7). So far the mechanism of action of ginseng is not clear because of the complex composition of ginseng extract (23).

The purpose of the present research was to determine the influence of long-term $P$. ginseng extract administration on the antioxidant response of muscle to exhaustive exercise in the rat. We evaluated GSH status and lipid peroxidation in terms of malondialdehyde (MDA) and mitochondrial citrate synthase (CS) and 3-hydroxyacyl-CoA dehydrogenase (HADH) activities. We observed that ginseng administration preserved mitochondrial function and decreased oxidative stress in muscle after exhaustive exercise.

\section{Material and Methods}

\section{Animals and treatments}

Male Wistar rats weighing on average $200 \pm 50 \mathrm{~g}$, supplied by Iffa Credo (Barcelona, Spain), were used. The animals were maintained 2 or 4 to a cage under controlled conditions of temperature $\left(20 \pm 3^{\circ} \mathrm{C}\right)$, and humidity (45-65\%) with a 12-h light-dark cycle (lights on 6:00 h). The feed consisted of a standard diet marketed by Panlab S.A. (Barcelona, Spain). Drinking water and food were provided ad libitum throughout the study. The standardized ginseng extract produced from $P$. ginseng C.A. Meyer roots, (G115 extract) was provided by Pharmaton S.A. (Lugano, Switzerland; Batch 1254/531). This ginseng extract contains $4 \%$ ginsenosides, as determined by HPLC (12). The roots of $P$. ginseng C.A. Meyer contain other compounds such as polysaccharides, peptides, polyacetylenic alcohols, fatty acids, and minerals.

Ginseng extract was administered daily for 3 months at the doses of 3,10,100, and 
$500 \mathrm{mg} / \mathrm{kg}$. Doses of 10 and $100 \mathrm{mg} / \mathrm{kg}$ are within the recommended range, but 3 and $500 \mathrm{mg} / \mathrm{kg}$ doses are outside to normal limits (of traditional oriental medicine prescriptions; 24). The extract was administered with an intragastric tube daily at 9:00 am. Since there was no reference compound or positive control available, two groups received only physiological saline solution, which was also the solution used to dissolve the extract, and were used as controls. At the end of the 3-month study period, the animals were subdivided into acutely exercised and non-exercised groups.

The animals were handled according to the principles of Council Directive 86/609 of the Ethics Committee concerning the Protection of Animals used for Experimental and other Scientific Purposes.

\section{Exercise protocol}

The rats ran on a treadmill at a speed of $20 \mathrm{~m} / \mathrm{min}$ with a gradient of $0 \%$ for a period of approximately $80 \mathrm{~min}$ per day. One week before the test, the rats were accustomed to treadmill running for 15 min a day, during the course of which the speed was gradually increased from 10 to $20 \mathrm{~m} / \mathrm{min}$ (25). The rats were divided into 8 animals per group as follows:

Resting. Control: no ginseng supplement, no exercise; $3 \mathrm{mg} / \mathrm{kg}$ ginseng, no exercise; $10 \mathrm{mg} / \mathrm{kg}$ ginseng, no exercise; $100 \mathrm{mg} / \mathrm{kg}$ ginseng, no exercise; $500 \mathrm{mg} / \mathrm{kg}$ ginseng, no exercise.

Acute exercise. Control: no ginseng supplement, exercise; $3 \mathrm{mg} / \mathrm{kg}$ ginseng, exercise; $10 \mathrm{mg} / \mathrm{kg}$ ginseng, exercise; $100 \mathrm{mg} / \mathrm{kg}$ ginseng, exercise; $500 \mathrm{mg} / \mathrm{kg}$ ginseng, exercise.

\section{Muscle analysis}

Under anesthesia with ip urethane (1.5 g/ $\mathrm{kg}$ body weight), the soleus, plantaris and gastrocnemius (red and white) muscles were extracted and frozen in liquid nitrogen for storage at $-80^{\circ} \mathrm{C}$ until analysis. The time elapsed from the end of treadmill exercise to anesthesia and muscle excision was 5-7 min. Soleus and red gastrocnemius are considered to be oxidative muscles since they are composed of type I and IIa fibers, whereas white gastrocnemius is a glycolytic muscle mainly composed of type IIb fibers, and plantaris is considered to be a mixed muscle composed of type I, IIa and IIb fibers.

\section{Determination of enzyme activity, glutathione status and lipid peroxidation}

Strenuous or exhaustive physical exercise increases free radical production; however, because of the difficulties in measuring free radicals by direct and reliable methods, it is necessary to use indirect methods such as MDA levels, GSH status and some enzymatic activities. Muscle from the right hind limb was weighed and homogenized in 0.1 $\mathrm{M}$ sodium phosphate buffer, $\mathrm{pH} 7.4$, after a 1:10 dilution (w/v). The tissue was homogenized and immersed in ice-cold water at $0^{\circ} \mathrm{C}$ with a Polytron (B Braun-Melsungen AG, Germany) and then centrifuged at $750 \mathrm{~g}$ to separate the cell membranes. The medium was frozen at $-80^{\circ} \mathrm{C}$ until analysis. Spectrophotometric assays were performed on a Hitachi U-2000 spectrophotometer (Tokyo, Japan) in 1-ml cuvettes, with a 1-cm light path. Reaction rates were proportional to protein concentrations. One unit of enzymatic activity is defined as the amount of enzyme that catalyzes the reaction of $1 \mu \mathrm{mol}$ of substrate per minute. CS (EC 4.1.3.7) activity, a marker of the tricarboxylic acid cycle, was measured at $37^{\circ} \mathrm{C}$ by the method of Srere et al. (26). HADH (EC 1.1.1.35) activity, a marker of ß-oxidation, was determined at $30^{\circ} \mathrm{C}$ according to the procedures described by Bradshaw and Noyes (27). All enzyme data are reported as $\mu \mathrm{mol} \mathrm{g}$ wet muscle ${ }^{-1} \min ^{-1}$.

GSH and oxidized glutathione disulfide 
(GSSG) were determined by HPLC at room temperature by the method of Reed et al. (28). Muscle samples ( 0.150 to $0.250 \mathrm{~g}$ ) were first transferred to a solution containing $2 \mathrm{mM}$ phenanthrolene and 7\% perchloric acid to avoid GSH oxidation. After homogenization, the samples were incubated at room temperature and 2,4 dinitrofluorobenzene was added to attach a chromophore to the amino groups. Peroxidative damage to cell lipid constituents was determined by measuring MDA concentration in muscle homogenates by the method of Buege and Aust (29). Briefly, an aliquot of the homogenate and $1 \mathrm{ml}$ of 2-thiobarbituric acidtrichloroacetic acid- $\mathrm{HCl}$ reagent were added to the centrifuge tubes and the mixture was kept at $100^{\circ} \mathrm{C}$ for $1 \mathrm{~h}$. After centrifugation at $3000 \mathrm{~g}$ for $10 \mathrm{~min}$, the absorbance of the supernatant was measured at $535 \mathrm{~nm}$. MDA concentration was calculated using $5 \mu \mathrm{M}$ tetramethoxypropane as standard.

\section{Statistical analysis}

Data are reported as means \pm SD. Twoway analysis of variance was performed on all variables. The significance of the difference between the means obtained was determined by the Newman-Keuls test. The level of significance was set at $\mathrm{P}<0.05$.

\section{Results}

The CS and HADH activities are shown in Table 1. Resting groups showed a significant increase in CS activity in soleus muscle $(\mathrm{P}<0.05)$ from $32.9 \pm 3.3$ to $39.8 \pm 3.7$ and from $39.3 \pm 3.3 \mu \mathrm{mol} \mathrm{g}$ muscle ${ }^{-1} \mathrm{~min}^{-1}$ after 10 and $100 \mathrm{mg} / \mathrm{kg}$ doses of ginseng extract. HADH was significantly increased $(\mathrm{P}<0.05)$ in soleus and red gastrocnemius muscles after the $100 \mathrm{mg} / \mathrm{kg}$ dose $(20.1 \pm 2.55,15.6 \pm$ 0.8 vs $12.4 \pm 0.4$ and $12.8 \pm 0.6 \mu \mathrm{mol} \mathrm{g}$ muscle $^{-1} \mathrm{~min}^{-1}$, respectively). Both activities were significantly decreased in practically all muscles studied in acutely exercised controls and in the group treated with $10 \mathrm{mg} / \mathrm{kg}$ ginseng. However, these activities were unchanged compared to the resting control group after acute exercise and administration of the $100-\mathrm{mg} / \mathrm{kg}$ dose of ginseng extract, with values of CS activity of $37.5 \pm 4.7$, $43.5 \pm 5.1 \mu \mathrm{mol} \mathrm{g}$ muscle ${ }^{-1} \mathrm{~min}^{-1}$ and HADH

Table 1. Oxidative enzyme activities of citrate synthase and 3-hydroxyacyl-CoA dehydrogenase in skeletal muscle of rats treated with ginseng extract.

\begin{tabular}{|c|c|c|c|c|c|}
\hline \multicolumn{3}{|c|}{ Resting } & \multicolumn{3}{|c|}{ Acutely exercised } \\
\hline Control & $\begin{array}{c}\text { Ginseng } \\
\text { (10 mg/kg) }\end{array}$ & $\begin{array}{c}\text { Ginseng } \\
(100 \mathrm{mg} / \mathrm{kg})\end{array}$ & Control & $\begin{array}{c}\text { Ginseng } \\
(10 \mathrm{mg} / \mathrm{kg})\end{array}$ & $\begin{array}{c}\text { Ginseng } \\
(100 \mathrm{mg} / \mathrm{kg})\end{array}$ \\
\hline
\end{tabular}

\begin{tabular}{|c|c|c|c|c|c|c|}
\hline \multicolumn{7}{|c|}{$\mathrm{CS}\left(\mu \mathrm{mol} g\right.$ muscle $\left.{ }^{-1} \mathrm{~min}^{-1}\right)$} \\
\hline Soleus & $32.9 \pm 3.3$ & $39.8 \pm 3.7^{*}$ & $39.3 \pm 3.3^{*}$ & $29.7 \pm 0.9$ & $22.6 \pm 1.2^{* \dagger \neq}$ & $37.5 \pm 4.7^{\dagger}$ \\
\hline Red gastrocnemius & $41.9 \pm 4.2$ & $51.9 \pm 5.2$ & $39.5 \pm 8.5$ & $17.9 \pm 1.6^{*}$ & $12.6 \pm 0.9^{* \ddagger}$ & $43.5 \pm 5.1^{\dagger}$ \\
\hline Plantaris & $37.7 \pm 7.1$ & $43.6 \pm 5.0$ & $41.7 \pm 3.8$ & $35.2 \pm 3.9$ & $20.2 \pm 1.4^{* \dagger \ddagger}$ & $37.7 \pm 3.6$ \\
\hline White gastrocnemius & $12.2 \pm 2.0$ & $18.2 \pm 1.8^{*}$ & $17.1 \pm 1.7$ & $14.1 \pm 1.3$ & $12.7 \pm 1.0^{\ddagger}$ & $17.9 \pm 3.3^{*}$ \\
\hline \multicolumn{7}{|c|}{ HADH ( $\mu \mathrm{mol} \mathrm{g}$ muscle $\left.{ }^{-1} \mathrm{~min}^{-1}\right)$} \\
\hline Soleus & $12.4 \pm 0.4$ & $12.0 \pm 0.6$ & $20.1 \pm 2.5^{*}$ & $8.9 \pm 0.7$ & $10.9 \pm 0.4$ & $18.3 \pm 2.2^{* \dagger}$ \\
\hline Red gastrocnemius & $12.8 \pm 0.6$ & $13.8 \pm 1.4$ & $15.6 \pm 1.8^{*}$ & $7.7 \pm 1.4^{*}$ & $7.9 \pm 1.2^{* \ddagger}$ & $19.5 \pm 1.0 * \S \dagger$ \\
\hline Plantaris & $8.8 \pm 0.7$ & $8.5 \pm 0.8$ & $8.8 \pm 0.5$ & $6.9 \pm 0.3^{*}$ & $6.8 \pm 0.8^{* \ddagger}$ & $8.6 \pm 0.8^{\dagger}$ \\
\hline White gastrocnemius & $3.0 \pm 0.3$ & $3.7 \pm 0.1^{*}$ & $3.0 \pm 0.3$ & $2.9 \pm 0.2$ & $3.0 \pm 0.5^{\ddagger}$ & $2.8 \pm 0.3$ \\
\hline
\end{tabular}

Rats received 10 or $100 \mathrm{mg} / \mathrm{kg}$ ginseng extract by gavage. Data are reported as means \pm SD for muscle obtained from 8 rats. CS $=$ citrate synthase; HADH = 3-hydroxyacyl-CoA dehydrogenase. ${ }^{*} \mathrm{P}<0.05$ compared to control resting group; ${ }^{\dagger} \mathrm{P}<0.05$ compared to control exercised group; ${ }^{\ddagger} \mathrm{P}<0.05$ between resting and exercise in ginseng $(10 \mathrm{mg} / \mathrm{kg}) .{ }^{\S} \mathrm{P}<0.05$ between resting and exercise in ginseng $(100 \mathrm{mg} / \mathrm{kg} ; \mathrm{Newman}-$ Keuls test). 
activity of $18.3 \pm 2.2,19.5 \pm 1.0 \mu \mathrm{mol} \mathrm{g}$ muscle ${ }^{-1} \mathrm{~min}^{-1}$ in soleus and red gastrocnemius.

The effectiveness of protection against lipid peroxidation depends on the tissue concentration of GSH and the reducing capacity of the GSH-GSSG cycle. The results presented in Table 2 show that ginseng administration did not increase basal GSH levels in resting rats, but a lower GSH content $(\mathrm{P}<$ 0.05 ) in soleus, gastrocnemius and plantaris was detected in the groups treated with the ginseng dose of $100 \mathrm{mg} / \mathrm{kg}$ after exercise. GSSG levels varied, without any clear tendency to a change caused by the effect of treatment and exercise.

Lipid peroxidation (measured on the basis of MDA levels) was higher in all muscles after acute exercise; however, ginseng extract had an important antioxidant effect after exhaustive exercise, as shown by the lower MDA levels (Figure 1). Acute exercise increased MDA levels $(\mathrm{P}<0.05)$ from $0.045 \pm 0.002$ to $0.132 \pm 0.02 \mu \mathrm{mol} / \mathrm{g}$ in the control group (soleus). Lower levels were detected in soleus muscle after administration of $100 \mathrm{mg} / \mathrm{kg}$ ginseng, ranging from
$0.021 \pm 0.001$ to $0.034 \pm 0.001 \mu \mathrm{mol} / \mathrm{g}$. Lower MDA levels $(\mathrm{P}<0.05)$ were detected after acute exercise in the muscles of animals treated with the $10-$ and $100-\mathrm{mg} / \mathrm{kg}$ doses of ginseng extract.

\section{Discussion}

The purpose of this research was to study the effects of oxidative stress induced by exhaustive exercise on muscle mitochondrial function and antioxidant response after long-term administration of the standardized ginseng extract. The most important finding of this in vivo study was that ginseng administration decreased the free radical generation in skeletal muscles after exhaustive exercise. In vitro studies $(7,8,14)$ have long reported that ginseng is a scavenger of free radicals and the present study showed this effect in rat tissues obtained in vivo.

Free radical damage in muscle is associated with multiple pathophysiological processes occurring in muscle diseases and with aging. Different types of skeletal muscles possess distinct morphological, physiological and biochemical properties. Mixed

Table 2. Glutathione content of rat soleus, gastrocnemius (red and white) and plantaris skeletal muscles.

\begin{tabular}{|c|c|c|c|c|c|c|c|c|c|c|c|}
\hline \multicolumn{3}{|c|}{ Soleus } & \multicolumn{3}{|c|}{ Red gastrocnemius } & \multicolumn{3}{|c|}{ Plantaris } & \multicolumn{3}{|c|}{ White gastrocnemius } \\
\hline GSH & GSSG & $\begin{array}{l}\text { GSH/ } \\
\text { GSSG }\end{array}$ & GSH & GSSG & $\begin{array}{l}\text { GSH/ } \\
\text { GSSG }\end{array}$ & GSH & GSSG & $\begin{array}{l}\text { GSH/ } \\
\text { GSSG }\end{array}$ & GSH & GSSG & $\begin{array}{c}\text { GSH/ } \\
\text { GSSG }\end{array}$ \\
\hline
\end{tabular}

\begin{tabular}{|c|c|c|c|c|c|c|c|c|c|c|c|c|}
\hline \multicolumn{13}{|l|}{ RESTING } \\
\hline $\begin{array}{l}\text { Control } \\
\text { Ginseng }\end{array}$ & $3.6 \pm 0.5$ & $0.13 \pm 0.03$ & $30 \pm 11$ & $2.2 \pm 0.4$ & $0.05 \pm 0.01$ & $41 \pm 11$ & $1.8 \pm 0.4$ & $0.07 \pm 0.02$ & $29 \pm 10$ & $1.4 \pm 0.2$ & $0.06 \pm 0.01$ & $20 \pm 0.1$ \\
\hline 10 mg/kg & $3.4 \pm 0.5$ & $0.08 \pm 0.01$ & $41 \pm 10$ & $1.9 \pm 0.2$ & $0.03 \pm 0.01$ & $67 \pm 12$ & $1.5 \pm 0.3$ & $0.02 \pm 0.01 *$ & $74 \pm 16$ & $1.1 \pm 0.3$ & $0.02 \pm 0.01 *$ & $49 \pm 13$ \\
\hline $100 \mathrm{mg} / \mathrm{kg}$ & $3.8 \pm 0.5$ & $0.06 \pm 0.03^{*}$ & $75 \pm 29$ & $2.0 \pm 0.7$ & $0.03 \pm 0.01^{*}$ & $77 \pm 26$ & $2.0 \pm 0.2$ & $0.03 \pm 0.01 *$ & $87 \pm 52^{*}$ & $1.3 \pm 0.3$ & $0.03 \pm 0.01 *$ & $53 \pm 18$ \\
\hline \multicolumn{13}{|c|}{ ACUTE EXERCISE } \\
\hline $\begin{array}{l}\text { Control } \\
\text { Ginseng }\end{array}$ & $3.5 \pm 0.4$ & $0.08 \pm 0.02$ & $45 \pm 14$ & $2.6 \pm 0.6$ & $0.03 \pm 0.01$ & $100 \pm 35^{*}$ & $1.7 \pm 0.2$ & $0.03 \pm 0.01 *$ & $54 \pm 10$ & $1.3 \pm 0.3$ & $0.04 \pm 0.01 *$ & $33 \pm 13$ \\
\hline 10 mg/kg & $3.8 \pm 0.7$ & $0.06 \pm 0.03^{*}$ & $56 \pm 14$ & $2.2 \pm 0.5$ & $0.04 \pm 0.01$ & $56 \pm 8$ & $1.7 \pm 0.1$ & $0.05 \pm 0.02 *$ & $26 \pm 25$ & $1.3 \pm 0.2$ & $0.04 \pm 0.005^{*}$ & $23 \pm 22^{\dagger}$ \\
\hline $100 \mathrm{mg} / \mathrm{kg}$ & $1.6 \pm 0.4^{* \# \#}$ & $0.08 \pm 0.02 *$ & $20 \pm 8^{\ddagger}$ & $1.1 \pm 0.3^{* \# \#}$ & $0.05 \pm 0.01$ & $23 \pm 10^{\# \neq}$ & $0.7 \pm 0.3^{* \# \neq}$ & $0.03 \pm 0.01 *$ & $24 \pm 4^{\ddagger}$ & $0.8 \pm 0.2$ & $0.04 \pm 0.005^{*}$ & $21 \pm 4^{\ddagger}$ \\
\hline
\end{tabular}

Data are reported as means \pm SD for muscle obtained from 8 rats. GSH and GSSG levels are reported as $\mu$ mol/g muscle. GSH $=$ glutathione; GSSG = oxidized glutathione (disulfide). ${ }^{*} P<0.05$ compared to control resting group. $\# P<0.05$ compared to control exercised group. ${ }^{\dagger} P<0.05$ between resting and exercise in ginseng $(10 \mathrm{mg} / \mathrm{kg}) .{ }^{\ddagger} \mathrm{P}<0.05$ between resting and ginseng $(100 \mathrm{mg} / \mathrm{kg}$; Newman-Keuls test). 
muscles (rich in IIa fibers) seem to be more susceptible to exercise-induced oxidative stress $(1,18)$. $P$. ginseng extract is known to increase capillary density and the oxidative capacity of muscles with greater aerobic potential (30). Acute pre-treatment of mice with crude extract increased their endurance in the swimming and running tests, but the reason for this increase was linked to the availability of muscle substrates and their utilization (31). In fact, in our previous experiments (11), running time after treatment with ginseng extract was significantly increased from $55 \pm 11 \mathrm{~min}$ in the control group to $102 \pm 20$ min after the administration of ginseng extract at the 10- and 100$\mathrm{mg} / \mathrm{kg}$ doses.

Lee et al. (10) reported that long-term administration of ginseng protected the liver cytosolic SOD, catalase and GSH peroxidase from age-related deterioration and antioxidant properties have been reported in ischemia-reperfusion injury in the rat brain (32). Long-term administration of ginseng extract inhibited decomposition of unsaturated fatty acid caused by iron- and hydrogen peroxide-induced lipid peroxidation. The antioxidant effect of ginseng extract may occur not only at the initiation of the radical chain reaction but also at the propagation stage (7). Ginseng administration significantly increased CS and HADH activities in oxidative muscles such as soleus and red gastrocnemius (Table 1). These activities are focused on mitochondria as the major site of free radical generation. Ferrando et al. (30) showed that ginseng extract increased mitochondrial density in rat oxidative muscles after a $50-\mathrm{mg} / \mathrm{kg}$ dose for three months. On the other hand, down-regulation in CS activity has been reported in muscle and liver measured by GSH depletion and mitochondrial oxidative damage (33). In the present study, a decrease in CS and HADH enzymatic activities was detected in control animals (no ginseng supplement) and in acutely exercised animals treated with ginseng extract $(10 \mathrm{mg} / \mathrm{kg})$ but the values for rats treated with $100 \mathrm{mg} / \mathrm{kg}$ ginseng extract remained unchanged after exercise. Fu and Ji (34) showed that a high dose $(2.5 \mathrm{~g} / \mathrm{kg})$ of ginseng (P. quinquefolium) was more effective in promoting antioxidant enzymes and in reducing reactive oxygen species production than a low dose $(0.5 \mathrm{~g} / \mathrm{kg})$ in heart, liver and muscle, although a precise dose-response effect could not be determined.

GSH is an important cytosolic compo-

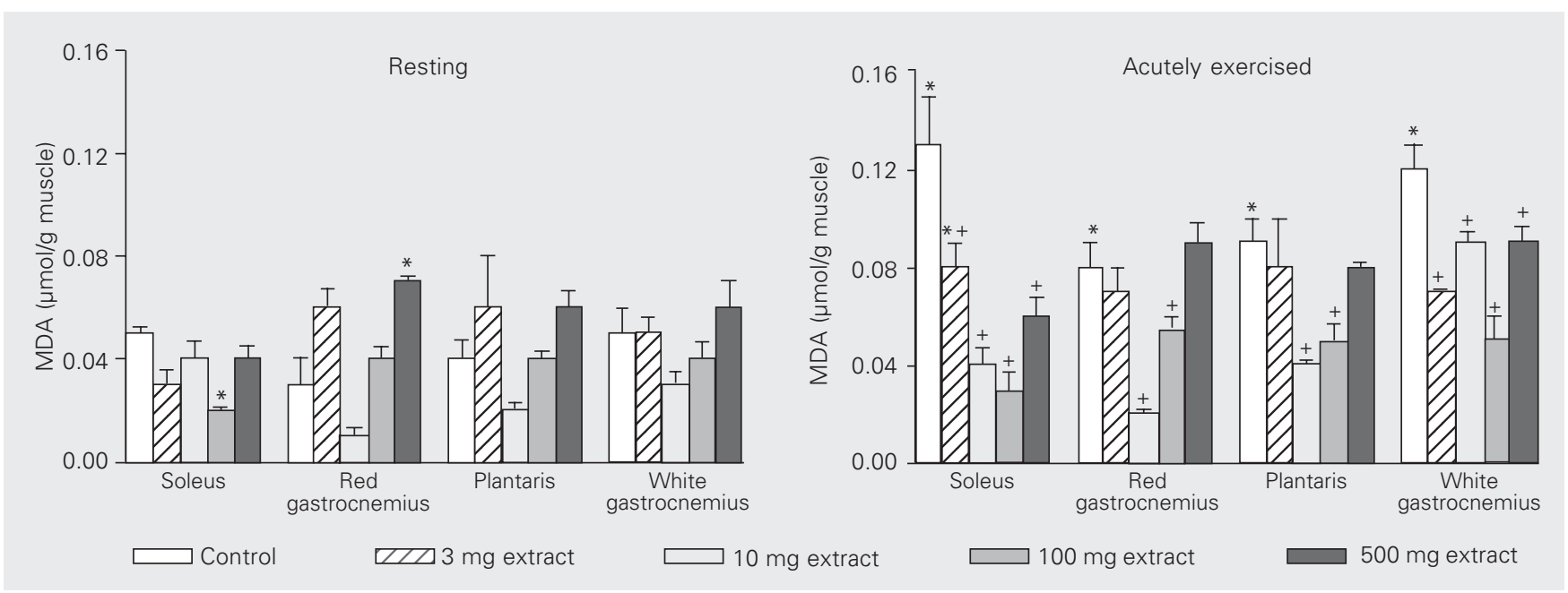

Figure 1. Lipid peroxidation content indirectly measured by the production of malondialdehyde (MDA) in hindlimb muscles from resting and exercised animals supplemented with 3,10,100, and $500 \mathrm{mg} / \mathrm{kg}$ ginseng extract by gavage. Data are reported as means \pm SD $\mu \mathrm{mol}$ MDA/g muscle for muscle from 8 rats. ${ }^{*} \mathrm{P}<0.05$ compared to resting control group. ${ }^{+} \mathrm{P}<0.05$ compared to exercised control group (Newman-Keuls test). 
nent that protects against damage by oxidative stress. GSH levels have been reported to decrease during physical exercise, especially in the liver (35). Strenuous exercise can promote GSH oxidation to GSSG in blood, liver and skeletal muscle. In agreement with Lee et al. (10), in the present study ginseng extract administration did not increase total GSH levels. However, after exhaustive exercise the animals treated with ginseng extract showed lower GSH levels. Both the workload involved and the duration of exercise may be important in eliciting disturbances in muscle GSH levels $(25,33)$. Our results agree with those obtained by Fu and Ji (34) who reported significant alterations in muscle GSH status after exhausting exercise performed for $120 \mathrm{~min}$, in rats treated with 10 and $100 \mathrm{mg} / \mathrm{kg}$ ginseng. A concomitant increase in GSSG was not observed.

Cells are capable of exporting GSSG to maintain the GSH:GSSG ratio and to alleviate the potential toxic effect of GSSG. This has been demonstrated in skeletal muscle, liver, heart, and erythrocytes (18). Our previous results showed that the GSH/GSSG ratio increased significantly in liver only after administration of the extract at the dose of $100 \mathrm{mg} / \mathrm{kg}$ (11).

Exhaustive exercises increase the concentration of lipid peroxides in skeletal muscle and plasma (16). The effect of acute exercise on MDA levels seems to be similar in both human and rat models and in the present study MDA levels were significantly increased in all muscles studied after exhaustive exercise, in agreement with other reports $(17,36)$. Concerning membrane integrity and damage induced by free radicals, ginseng may stabilize the lipid structure of the membrane perturbed by the attack of free radicals. This stabilizing effect was reflected by the decreased MDA levels after acute exercise obtained with the administration of the $10-$ and $100-\mathrm{mg} / \mathrm{kg}$ doses in all muscles studied. The muscles showing the highest protection through decreases in MDA levels were the soleus and the red gastrocnemius. These muscles are mainly composed of type I and IIa fibers and show the highest antioxidant capacity (35).

Long-term administration of ginseng extract exhibited antioxidant capacity. Since free radicals have a very short half-life, we measured antioxidant capacity indirectly by determining MDA levels. According to Jiang et al. (37), the degree of antioxidant action shown by the main saponins is $R b_{1}>R_{2}>R b_{3}$. In contrast, in a study of Vietnamese ginseng, Huong et al. (6) concluded that the minor components contained in this species, and not the main saponin, are responsible for the inhibition of MDA formation (brain and liver).

A possible mechanism that could be invoked to explain the suppression of lipid peroxidation is through the inhibition of enzymes such as lipoxygenase involved in the metabolism of unsaturated fatty acids such as arachidonic acid to prostaglandins. Ginseng has well-known anti-inflammatory actions $(12,38)$, an effect probably caused by a decrease in phospholipase $\mathrm{A}_{2}$ activity (39) and by the reinforcement of muscle fiber membranes, as also observed for prednisone, another anti-inflammatory agent (40).

Attele et al. (1) reported the ability of ginsenosides to target the cell membrane and to freely cross it, modifying its physical properties, interacting directly with membrane proteins, and even becoming incorporated into membranes.

Mei et al. (41) showed that ginsenosides exert a protective effect on endothelial cell damage generated by the xanthine-xanthine oxidase reaction measured by the reduced concentration of MDA. Our results showed that the damage-preventing effect is not dose related and did not occur at the dose of 500 $\mathrm{mg} / \mathrm{kg}$.

The long-term administration of ginseng extract was able to protect muscle from exercise-induced oxidative stress independent of fiber type but the mechanism of the antioxi- 
dant activity of ginseng extract is still unclear. In the present investigation, we studied the overall effects of a standardized ginseng extract. The antioxidant action of ginseng is complex since ginsenosides and other constituents of ginseng may show many kinds of biological activity. In fact, ginseng extract contains several groups of compounds other than ginsenosides, such as phenolic substances (maltol, salicylic acid, vanillic acid), with direct and indirect consequences in terms of antioxidant activity $(6,24)$. Therefore, the exact mechanism of action of ginseng remains unclear because of the complex composition of the extract.

Actually it is important to study the role of compounds of nutritional or pharmacological relevance by focusing on the potentiation of cellular antioxidant defense against toxins and various diseases. The model established in the present study to induce oxidative stress and muscle tissue damage was exhaustive exercise. The muscle antioxidant response after acute exercise is controversial since transcriptional activation, protein content and enzyme activities are strongly influenced by the intracellular environment. Strenuous exercise promotes the production of free radicals in muscle and long-term ginseng administration seems to stabilize membranes and to protect mitochondrial function in skeletal muscle.

\section{Acknowledgments}

The authors thank Pharmaton S.A. (Lugano, Switzerland) for the generous gift of Panax ginseng extract.

\section{References}

1. Attele AS, Wua JÁ \& Yuan CS (1999). Ginseng pharmacology, multiple constituents and multiple actions. Biochemical Pharmacology, 58: 1685-1693.

2. Gillis CN (1997). Panax ginseng pharmacology: a nitric oxide link? Biochemical Pharmacology, 54: 1-8.

3. Shin HR, Kim JY, Yun TK, Morgan G \& Vainio H (2000). The cancerpreventive potential of Panax ginseng: a review of human and experimental evidence. Cancer Causes and Control, 11: 565-576.

4. Kim YH, Park KH \& Rho HM (1996). Transcriptional activation of the $\mathrm{Cu}, \mathrm{Zn}$-superoxide dismutase gene through the $\mathrm{AP}_{2}$ site by ginsenoside $\mathrm{Rb}_{2}$ extracted from a medicinal plant, Panax ginseng. Journal of Biological Chemistry, 271: 24539-24543.

5. Chang MS, Lee SG \& Rho HM (1999). Transcriptional activation of $\mathrm{Cu} / \mathrm{Zn}$ superoxide dismutase and catalase genes by panaxadiol ginsenosides extracted from Panax ginseng. Phytotherapy Research, 13: 641-644.

6. Huong NT, Matsumoto K, Kasai R, Yamasaki K \& Watanabe $H$ (1998). In vitro antioxidant activity of Vietnamese ginseng saponin and its components. Biological Pharmaceutical Bulletin, 21: 978981.

7. Zhang YG, Yasuda $T$, Yu Y, Zheng P, Kawabata T, Ma Y \& Okada S (1996). Ginseng extract scavenges hydroxyl radical and protects unsaturated fatty acids from decomposition caused by iron-mediated lipid peroxidation. Free Radical Biology and Medicine, 20: 145150.

8. Chen X (1996). Cardiovascular protection by ginsenosides and their nitric oxide releasing action. Clinical and Experimental Pharmacology and Physiology, 23: 728-732.

9. Maffei Facino R, Carini M, Aldini G, Calloni MT \& Berti F (1999). Panax ginseng administration in the rat prevents myocardial ische- mia-reperfusion damage induced by hyperbaric oxygen: evidence for an antioxidant intervention. Planta Medica, 5: 614-619.

10. Lee HJ, Kim DY \& Chang CC (1999). Antioxidant effects of Korean red ginseng components on the antioxidant enzymes activity and liver peroxidation in the liver of mouse treated with paraquat. Journal of Ginseng Research, 23: 182-189.

11. Voces J, Alvarez Al, Vila L, Ferrando A, Cabral C \& Prieto JG (1999). Effects of administration of the standardized Panax ginseng extract G115 on hepatic antioxidant function after exhaustive exercise. Comparative Biochemistry and Physiology, 123: 175-184.

12. Cabral de Oliveira AC, Perez AC, Merino G, Prieto JG \& Alvarez A (2001). Protective effects of Panax ginseng on muscle injury and inflammation after eccentric exercise. Comparative Biochemistry and Physiology, 130C: 369-377.

13. Keum YS, Park KK, Lee JM, Chun KS, Park JH, Lee SK, Kwon H \& Surh YJ (2000). Antioxidant and antitumor promoting activities of the methanol extract of heat-processed ginseng. Cancer Letters, 150: $41-48$

14. Kitss DD, Wijewickreme AX \& Hu C (2000). Antioxidant properties of a North American ginseng extract. Molecular and Cellular Biochemistry, 203: 1-10.

15. Stangel M, Mix E, Zettl UK \& Gold R (2001). Oxides and apoptosis in inflammatory myopathies. Microscopy Research and Technique, 55: 249-258.

16. Alessio HM (1993). Exercise-induced oxidative stress. Medicine and Science in Sports and Exercise, 25: 218-224.

17. Kayatekin BM, Gönenc S, Acikgöz O, Uysal N \& Dayi A (2002). Effects of sprint exercise on oxidative stress in skeletal muscle and liver. European Journal of Applied Physiology, 87: 141-144.

18. Powers SK, Ji LL \& Leeuwenburgh C (1999). Exercise training- 
induced alterations in skeletal muscle antioxidant capacity: a brief review. Medicine and Science in Sports and Exercise, 31: 987-997.

19. Hawley JA (2002). Adaptations of skeletal muscle to prolonged intense endurance training. Clinical and Experimental Pharmacology and Physiology, 29: 1-5.

20. Ji LL (1999). Antioxidant and oxidative stress in exercise. Proceedings of the Society for Experimental Biology and Medicine, 222: 283-292.

21. Dekkers JC, Doornen LJP \& Kemper HCG (1996). The role of antioxidant vitamins and enzymes in the prevention of exercise-induced muscle damage. Sports Medicine, 21: 213-238.

22. Carmeli E, Lavian G \& Reznick AZ (2000). The role of antioxidant nutrition in exercise and aging. In: Radak Z (Editor), Free Radicals in Exercise and Aging. Human Kinetics, Champaign, IL, USA.

23. Kim YK, Guo Q \& Packer L (2002). Free radical scavenging activity of red ginseng aqueous extracts. Toxicology, 172: 149-156.

24. Mahady GB, Gyllenhaal C, Fong HHS \& Farnsworth NR (2000). Ginsengs: A review of safety and efficacy. Nutritional and Clinical Care, 3: 90-101.

25. Ji LL \& Fu R (1992). Responses of glutathione system and antioxidant enzymes to exhaustive exercise and hydroperoxide. Journal of Applied Physiology, 72: 549-554.

26. Srere PA, Brazil A \& Boneu L (1963). The citrate condensing enzyme of pigeon breast muscles and moth flight muscle. Acta Chemica Scandinavica, 14: 17-19.

27. Bradshaw RA \& Noyes BE (1973). 3-Hydroxyacyl CoA dehydrogenase from pig heart muscle. Journal of Biological Chemistry, 248: 3052-3054.

28. Reed DJ, Babson JR, Beatty PW, Brodie AE, Ellis WW \& Potter DW (1980). High-performance liquid chromatography analysis of nanomole levels of glutathione, glutathione disulfide, and related thiols and disulfides. Analytical Biochemistry, 106: 55-62.

29. Buege JA \& Aust SD (1978). Microsomal lipid peroxidation. Methods in Enzymology, 52: 302-310.

30. Ferrando A, Vila L, Voces JA, Cabral AC, Alvarez AI \& Prieto JG
(1999). Effects of standardized Panax ginseng extract G115 on the skeletal muscle of the rat: A comparative study in animals at rest and under exercise. Planta Medica, 65: 1-6.

31. Wang LCH \& Lee T (1998). Effect of ginseng saponins on exercise performance in non-trained rats. Planta Medica, 64: 130-133.

32. Zhang YG \& Liu TP (1994). Protective effects of total saponins of $P$. ginseng on ischemia-reperfusion injury in rat brains. Clinical Journal of Pharmacology and Toxicology, 8: 7-12

33. Leewenburgh C \& Ji LL (1995). Glutathione depletion in rested and exercised mice: biochemical consequence and adaptation. Archives of Biochemistry and Biophysics, 316: 941-947.

34. Fu Y \& Ji LL (2003). Chronic ginseng consumption attenuates ageassociated oxidative stress in rats. Journal of Nutrition, 11: 3603 3609.

35. Ji LL, Fu R \& Mitchell EW (1992). Glutathione and antioxidant enzymes in skeletal muscle: effects of fiber type and exercise intensity. Journal of Applied Physiology, 73: 1854-1859.

36. Green HJ (1997). Mechanism of muscle fatigue in intense exercise. Journal of Sport Science, 15: 247-256.

37. Jiang $Y$, Zhong GG, Chen $L$ \& Ma XY (1992). Influences of ginsenosides $R b_{1}, R b_{2}$ and $R b_{3}$ on electric and contractile activities of normal and damaged cultured myocardiocytes. Zhongguo YaoLi XueBao, 13: 403-406.

38. Matsuda H, Samukawa K \& Kubo M (1990). Anti-inflammatory activity of ginsenoside Ro. Planta Medica, 56: 19-23.

39. Li SH \& Chu Y (1999). Anti-inflammatory effects of total saponins of Panax notoginseng. Chung Juo Yao Li Hsueh Pao, 20: 551-554.

40. Jacobs SCJM, Bootsma AL, Willems PWA, Bar PR \& Wokke JHJ (1996). Prednisone can protect against exercise-induced muscle damage. Journal of Neurology, 243: 410-416.

41. Mei B, Wang YF, Wu JX \& Chen WZ (1994). Protective effects of ginsenosides on oxygen free radical induced damages of cultured vascular endothelial cells in vitro. Yao Hsueh Hsueh Pao, 29: 801808 . 